\title{
Evolution of Scrum Transcending Business Domains and the Future of Agile Project Management
}

\author{
Richard J. J. Oprins ${ }^{1(\bowtie)}{ }^{\left(H^{\prime}\right.}$ Helena A. Frijns ${ }^{2}$, and Christoph J. Stettina ${ }^{1,2,3(\bowtie)}$ \\ 1 Leiden Institute of Advanced Computer Science, Leiden University, \\ Niels Bohrweg 1, 2333 CA Leiden, The Netherlands \\ r.j.j.oprins@gmail.com, c.j.stettina@fgga.leidenuniv.nl \\ ${ }_{2}$ Centre for Innovation The Hague, Leiden University, \\ Schouwburgstraat 2, 2511 VA The Hague, The Netherlands \\ 3 Accenture B.V., Orteliuslaan 1000, 3528 BD Utrecht, The Netherlands
}

\begin{abstract}
The growing popularity of Agile management methods has led to their application to a number of areas inside, but also outside, the software development domain. However, despite many practitioner reports, research exploring whether and how Agile practices have been applied in domains beyond software development has been rather patchy with little empirical evidence. What is there behind the hype and how can other domains learn from it? To address this gap in the research, we present the findings of our study on the application of Agile management practices in other domains, including an outlook towards a potential expansion enabling Business Agility. To practitioners, this study presents examples of Scrum applied outside the software development domain including concrete practices applied. To researchers, it presents an empirical starting point for further exploration.
\end{abstract}

Keywords: Agile $\cdot$ Agile practices $\cdot$ Business agility $\cdot$ Change $\cdot$

Client orientation $\cdot$ Collaboration $\cdot$ Responsiveness $\cdot$ Retrospectives $\cdot$

Scrum outside software development

\section{Introduction}

In 2001, a meeting in a ski resort in Utah (United States) resulted in an agreement that changed the way software development would unfold, and which would, eventually, transform ways of working not solely in the field of management. This agreement was based on the practices of collaborative, self-organising efforts being undertaken by cross-functional teams who would not only consult with their customers and end users, but would also be self-reflecting, selfresponsive and self-improving. This agreement is known as the Agile Manifesto [1], and it promoted 12 simple principles and four values. These principles were formulated as a direct response to the traditional waterfall methods of business planning and execution.

(C) The Author(s) 2019

P. Kruchten et al. (Eds.): XP 2019, LNBIP 355, pp. 244-259, 2019.

https://doi.org/10.1007/978-3-030-19034-7_15 
Given that Agility has come to be viewed in a wider context, as something more than a series of techniques, it is not surprising that many now consider it to be a fundamentally transformative management philosophy [2]. It is a dynamic process that has not only revolutionised software development, but is also equipping organisations and the people who manage them to respond quickly and appropriately in a world in which the pace of change is increasing exponentially day by day.

This article focuses on practical applications, examining how Agile practices have been implemented in domains beyond those related to software development. Using research findings, it also discusses what characterises those organisations that have applied Agile methods and, using empirical cross-case data and existing literature, it defines and describes the most commonly applied practices. Based on 18 interviews conducted with Agile practitioners from a variety of domains who are involved in business processes such as marketing, sales, communication and human resources, this article, through its analysis of the concrete impact of Agile methods, expands the current understanding of Agile project management methods, thus encouraging further exploration into future Agile implementation.

\section{Related Work}

While a lot of research work has been focused on expanding Agile methods within the software development and information systems domain [3,4], the application of Agile ways of working outside the IT sphere is relatively new. It is a subject that remains to be investigated, since exploration of Agile methods in different domains is supported only by scattered reports and by little empirical evidence.

One of the difficulties of identifying the application of Agile methods beyond IT is the expansion of information systems into other domains. For example, marketing is nowadays often driven by automation and supported by data engineers and software development teams (e.g. to automatically analyse and act upon responses from social media or automated mailing lists). This blurs the lines between marketing and software development. In one of the few contributions to the research, Conforto et al. [5] present a set of enablers for the application of Agile project management methods outside IT.

Further, due to their practical nature, Agile methods can be difficult to understand, and to delineate what is Agile and what is not is not an obvious undertaking $[6,7]$. While Agile project and portfolio management has an impact on the processes (practices applied in context), structures (roles and responsibilities) and culture (values and principles) in organisations [8], in this article we follow the advice of Laanti et al. [9] and focus on the behavioural components and specifically the Agile practices applied. We do so because Agile practices can be viewed as the most tangible elements of agility and as such can be easier to pinpoint by research participants. Even though a description of Agile practices can be found elsewhere [10,11] the most commonly applied Agile practices are [12]: (1) Iteration Planning; (2) Iterative Development; (3) Continuous Integration 
\& Testing; (4) Co-Location; (5) Stand-up Meetings; (6) Customer Access; (7) Customer Acceptance Tests; and (8) Retrospectives [11,12].

In the remainder of this section an analysis of the current state of knowledge is followed by a description of the gaps in the available literature, all of which led to the iteration of the research questions that formed the focus of our study. This research focused principally on (1) scientific and empirical contributions and (2) practitioner reports.

\subsection{Scientific Reports}

In our literature study we found studies conducted in the domains of Education, Sales and Manufacturing. The results are presented here.

Sales: Solingen, Sutherland, and de Waard [13] studied the application of Scrum in the sales domain, where Scrum rituals, such as short iterations, Sprint reviews, checking on progress and attending a daily stand-up meeting were adopted in relation to such activities. The application of Scrum enabled sales to become more predictable and revealed new ways of conducting sales with customers, thus exposing the relationships that existed between customer maintenance and referrals for new business. A study by Steenberg [14] revealed that Agile methods, when used to survey customer needs, provided invaluable feedback that could be used to improve client focus and to give sales teams insight into how their behaviour positively or negatively impacted clients, thus enabling the teams to quickly make changes and become more effective.

Education: Although the application of Agile methods is found in educational software development, some studies looked at Agile applications in teaching methods. Melnik and Maurer [15] studied the effect of XP practices on secondyear academic students and their perception of the use of XP practices. They selectively adopted XP practices such as test-driven development; simple design; continuous integration; refactoring; pair programming; and collective code ownership. Based on the results, Melnik and Maurer concluded that Agile methods in the schools sphere must be specifically tailored to an educational context, in contrast to what took place in terms of industry. Several studies have looked at the use of altered versions of Scrum [16] and studied the impact of implementing Agile in research groups. These studies applied Scrum rituals such as daily scrum, sprint review and sprint planning. The use of Scrum had the effect of ensuring that faculty time was used more efficiently and that students improved their productivity. It helped students to be more involved and teachers to focus on helping and coaching their students which, in turn, helped them to propel the student's research forward. Students also started helping each other on their tasks and developed effective strategies to deliver their work on time. Stettina et al. [17] compared the impact of group sizes in relation to the use of Scrum rituals at universities, and in particular, analysed coaching and team routines. Coaching smaller teams took additional time, but improved the exchange of information and student satisfaction, all of which enhanced the maturity of the team. 
Manufacturing: Studies analysed how the application of Agile methodology was evolving and looked at methods such as the application of Real Agile Manufacturing [18] and supply chain management [19]. Besides these studies, research was also carried out on the issues that should be considered when Agile is being fully embraced [19]. Manivelmuridaren [20] concluded that Agile manufacturing methods differed so markedly from traditional manufacturing that he described it as a paradigm shift. The results of these studies indicated that, overall, Agile methods of manufacturing change an organisation by placing the customer, and not the company, at the centre of the manufacturing process. To embrace the required changes, employers must build a flexible organisation that can move human and physical resources around very quickly, when needed. In another research case undertaken by Inmana, Samuel, Saleb, Green and Whittend, the analysts studied manufacturing organisations which had become more Agile by implementing just-in-time purchase and manufacturing processes, an approach which improved the operating performance of the firm [21].

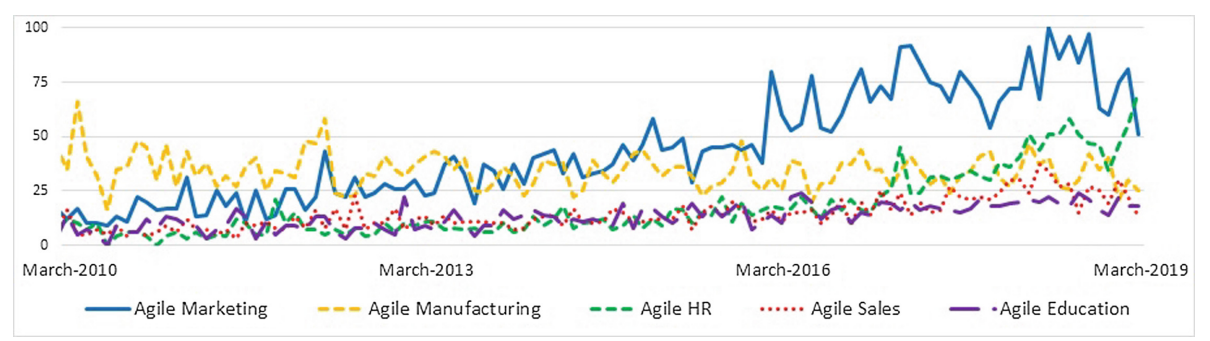

Fig. 1. Google search inquiries 2010-2019: Agile marketing (Blue), Agile manufacturing (Yellow), Agile HR (Green), Agile sales (Red), and Agile education (Purple) (Color figure online)

\section{$2.2 \quad$ Practitioner Reports}

Despite many practitioner reports and potential interest (see Fig.1), we found little empirical literature on the application of Agile methods, especially in the domains of marketing, healthcare, finance and human resources. Most of the reports relating to these four domains consist of accounts of personal experiences recorded in specialist blogs, forum discussions and opinion pieces, and thus are not the result of scientific study but presentations of personal views.

Marketing: Drumont [22] has blogged about her experience with marketeers, who are constantly trying to become faster and more nimble in their responses. This is especially important in the digital domain, where the days of executing static campaigns that have been planned months in advance are gone. Another document describing the Agile way of working is a marketing manifesto [23].

Healthcare: King and King [24] describe the use of Scrum in a medical family practice, brought into play to improve the skills of professionals by being transparent and using feedback received from peers. Another interesting case study is 
that of the Dutch healthcare organisation Buurtzorg. They use Agile principles such as self-managing teams, client focus and the use of small teams to review and discuss cases and problems in order to improve their performance [25].

Finance: In a blog post, Hegarty [26] describes how Scrum methods have been implemented in relation to teams of accountants, with the use of story-maps, sprints and retrospectives.

HR: In the human resources (HR) domain, one article posted on the Scrumstudy website describes how HR teams can benefit from Scrum [27]. The absence of literature on Agile in HR has also been acknowledged by Gothelf in the Harvard Business School article 'How HR can become Agile and Why it needs to' [28].

\subsection{Gaps in the Literature and Our Research Question}

To summarise, while there are numerous practitioner reports pointing to the application of Agile methods in different domains, existing empirical research contributions are limited to manufacturing, logistics, sales [13], education [15,17] and research [29]. Based on the state of the literature, we thus posed the following research question: In which domains can Agile management methods be found and what concrete practices/rituals have been applied to projects outside of the IT domain?

\section{Methodology}

The subject of this research involves a new environment from which not much empirical evidence is available. To study this organisational phenomenon within teams using Agile as way of working, the authors decided to follow a qualitative research approach. The data was collected using semi-structured interviews with open-ended questions; initial questions were followed by the posing of additional questions, which emerged as a result of the information provided in the initial interviews.

Identification and Selection of Interview Participants: Interview participants and the list of final interviewees were selected on the basis of internet searches and the use of information and contacts via the researchers' personal networks.

Internet Search: After an initial literature review, the researchers, using Google and LinkedIn, identified potential interviewees through the application of such relevant search terms as 'Scrum', 'Kanban', 'XP' and 'Agile', especially in contexts outside software development; references to Agile methods in general were found in the fields of construction, human resources, manufacturing, marketing, education and sales. One criterion that necessitated the exclusion of a particular participant was clear proof that the individual did not possess the claimed expertise in applying these methods within his/her domain. The resulting pool of interviewees was chosen on the basis of familiarity with the implementation 
of Agile methods (such as Scrum); professional experience in non-IT domains in which Agile methods of working had been applied; and specialised knowledge of the application of Agile methods outside software development; and/or research conducted in this area.

Use of Personal Network: The researchers also identified potential participants from their own personal networks and these individuals were asked if they knew anyone with similar experience or if they had clients who might be interested in being interviewed.

Invitations to participate were sent to 37 people from 22 different organisations, along with the following screening questions:

1. Are you familiar with the application of Agile methods outside IT projects? If yes, in which domain?

2. Are there any people in your organisation who have initiated Agile methods in other departments/domains (for example in marketing, sales, business, communication, etc.) or in schools?

3. Can you refer us to any other people/organisations that have implemented Agile methods?

The resulting pool of participants was made up of (among others) managers, Agile coaches and consultants and researchers who had been or were currently involved in the application of Agile methods such as Scrum in contexts beyond the domain of IT (see Table 1).

Table 1. Overview of participants

\begin{tabular}{|c|c|c|c|c|}
\hline Participant & Role & $\begin{array}{l}\text { Agile exp. } \\
\text { (in years) }\end{array}$ & $\begin{array}{l}\text { Industry application } \\
\text { of Agile methods }\end{array}$ & Domain application \\
\hline 1 & Consultant & $?$ & Local government and related organisations & Event management \\
\hline 2 & Agile coach & ? & Financial industry & Marketing \\
\hline 3 & Agile coach & $?$ & Financial industry & Marketing \\
\hline 4 & $\begin{array}{l}\text { Consultant, } \\
\text { Agile coach }\end{array}$ & 10 years & $\begin{array}{l}\text { Manufacturing, Product Development, } \\
\text { Transportation, Finance }\end{array}$ & $\begin{array}{l}\text { Product development, R\&D manufacturing, } \\
\text { Procurement }\end{array}$ \\
\hline 5 & Consultant & 5 years & Finance & Marketing \\
\hline 6 & Program Manager & 6 years & Energy & E-commerce, Online sales \\
\hline 7 & $\begin{array}{l}\text { Consultant, } \\
\text { Writer }\end{array}$ & $>10$ years & Administration & \\
\hline 8 & PhD Student & 1 year & Product development, Research & Research project \\
\hline 9 & Public speaker & $>10$ years & Various & Marketing, Sales, Start-ups \\
\hline 10 & $\begin{array}{l}\text { Manager of methods, } \\
\text { quality and technology }\end{array}$ & 7 years & Food retail & HR \\
\hline 11 & Consultant, Writer & $>10$ years & Various & Machine manufacturing, Sales and marketing \\
\hline 12 & $\begin{array}{l}\text { Manager } \\
\text { Senior product owner }\end{array}$ & 7 years & $\begin{array}{l}\text { Financial industry } \\
\text { Insurance }\end{array}$ & $\begin{array}{l}\text { Sales } \\
\text { Internet }\end{array}$ \\
\hline 13 & Consultant & 7 years & Financial industry & Marketing \\
\hline 14 & Consultant & 9 years & $\begin{array}{l}\text { Energy, } \\
\text { Manufacturing }\end{array}$ & Geology \\
\hline 15 & $\begin{array}{l}\text { Head of } \\
\text { communication team }\end{array}$ & 1 year & Education & Communication \\
\hline 16 & Agile coach & 5 years & Education & Schools \\
\hline 17 & Marketing manager & 3 years & Travel industry & Marketing \\
\hline 18 & $\begin{array}{l}\text { Consultant, (Scrum master) } \\
\text { Writer }\end{array}$ & 10 years & $\begin{array}{l}\text { Telecom } \\
\text { Software hosting }\end{array}$ & Customer Service, HR \\
\hline
\end{tabular}


Data Collection: The interviews were scheduled to fit the agenda of the respondents, took about $60 \mathrm{~min}$ and were held in the period between February and November 2017. Interview guides contained questions such as: Do you have experience of implementing Agile methods/Scrum outside of IT in your organisation? Can you give us concrete example(s)? How and why did you start applying Agile methods/Scrum outside of IT? What practices/routines/rituals/ceremonies did you implement? What were the barriers to adoption? Seven interviews were held via Skype, four by means of phonecalls and eight at face-to-face meetings. Audio recordings were made of the interviews with the participants' verbal consent. The audio recordings were transcribed by one of the researchers. The content of the transcribed interviews was sent to participants to make sure that the transcriptions did not misrepresent what they had intended to say. Participant 4 submitted four minor revisions, and participant 14 submitted two minor revisions. The transcribed interviews were anonymised for further textual analysis.

Data Analysis: During the course of this research, we interviewed 18 participants who worked in applying Agile management methods in the domains of marketing (6 cases); sales (2 cases); education (3 cases); human resources (2 cases); communication (1 case); event management (1 case); R\&D (1 case), change management (1 case); and geology (1 case). As depicted in Table 1 , the participants had on average about 5 years of relevant experience and worked in different industrial sectors, including finance, energy/utilities, education, the public sector and research. When adopting Agile methods across different domains, the vast majority of respondents indicated that they leaned on the Scrum framework as a starting point. The data was coded using an axial coding technique as described by Strauss and Corbin [30] resulting in a total of 144 pages of transcripts, over $18 \mathrm{~h}$ of recordings, and in total, 1089 codes.

The transcribed interviews were processed by one researcher. Two researchers analysed the transcriptions in search of results that would answer the following questions and which could be sorted according to the following categories: (1) methods used; (2) motivation; (3) change design; (4) success factors; (5) impact; and (6) practices. As it can be difficult to delineate what is Agile and what is not, we followed the advice of Laanti et al. [7] and compared the concrete practices applied.

\section{Results and Discussion}

The most commonly mentioned reasons given by participants to adopt Agile ways of working in their teams were: (1) external threats and fluctuating customer needs; (2) a lack of transparency about the value that was being delivered and how it connected to other organisational units; (3) the realisation that previously applied project management approaches did not work; and (4) the quest for increased employee satisfaction. As depicted in Table 2, the most applied practices were: structuring work in sprints $(\mathrm{n}=15)$, daily stand-up meetings $(\mathrm{n}=15)$, retrospectives $(\mathrm{n}=15)$ and sprint planning $(\mathrm{n}=14)$. 
The most alternated practices were: daily stand-up meetings, sprint planning and the retrospective. The biggest reasons for alternation of practices among our cases were mobility (travelling team members prefer calls) and perceived usefulness. The success of Agile practices can be linked to Agile maturity as participant 18 points out: "Scrum is introduced in many forms. This sometimes creates scepticism. Scrum was not always a success and this reflects on people's emotions. When rituals are removed and it didn't work, it is blamed on Scrum."

The remainder of this section elaborates on (1) the domains of application and the concrete Agile practices applied across our cases; and (2) the basis of trends in the work field, discussing domains where one could expect to encounter the application of Agile management in the future.

\subsection{Scrum Outside Software Development: Domains and Practices}

In this section we discuss the six domains where we encountered the application of Scrum (marketing, sales, education, human resources, communication and geology) and which concrete practices had been applied. In several cases the rituals were altered or not used anymore. These changes varied from adjusting the time of the daily stand-up meeting to the decision to stop rituals. An overview of the rituals and practices we observed through the interview process can be found in Table 2 .

Marketing: In marketing, the most applied rituals were the retrospective, mentioned by six out of the seven participants, followed by the use of iterations and the daily Scrum (stand-up) which was mentioned by seven respondents. Sprint planning was carried out by three out of the six respondents. Marketing had the most applications of an Agile way of working, but the rituals were not mentioned as frequently as in other domains. Participant 17 describes the application of cross-functional teams in the marketing department of a travel agency as follows: "[..] the commercial department consists of four bases (Tribes: Core, direct, partner and passenger). These bases are responsible for the products, experience of the direct sales to the customer, service during the ticket sales, interfaces to third parties and the aftersales. [..] A Crew is a multifunctional team, product developer (product owner), content, communication and data specialist. Their goal is to create value in a benefit for a specific subject."

Sales: We found four examples of sales departments changing their way of working to adopt an Agile approach. Almost all respondents mentioned that they implemented all the Scrum rituals, that is, they followed all the rules and processes described in the Scrum Guide [10]. One of the respondents mentioned that, after one implementation, the team was then free to alter how the rituals were implemented. This was based on the Shu-Ha-Ri principle, which states that a team first learns the rules and that later it can bend the rules. One respondent described a situation in a team where team members found it difficult to speak out: "The team was not able to speak out about the previous sprint. They found 
Table 2. Agile practices across the identified domains

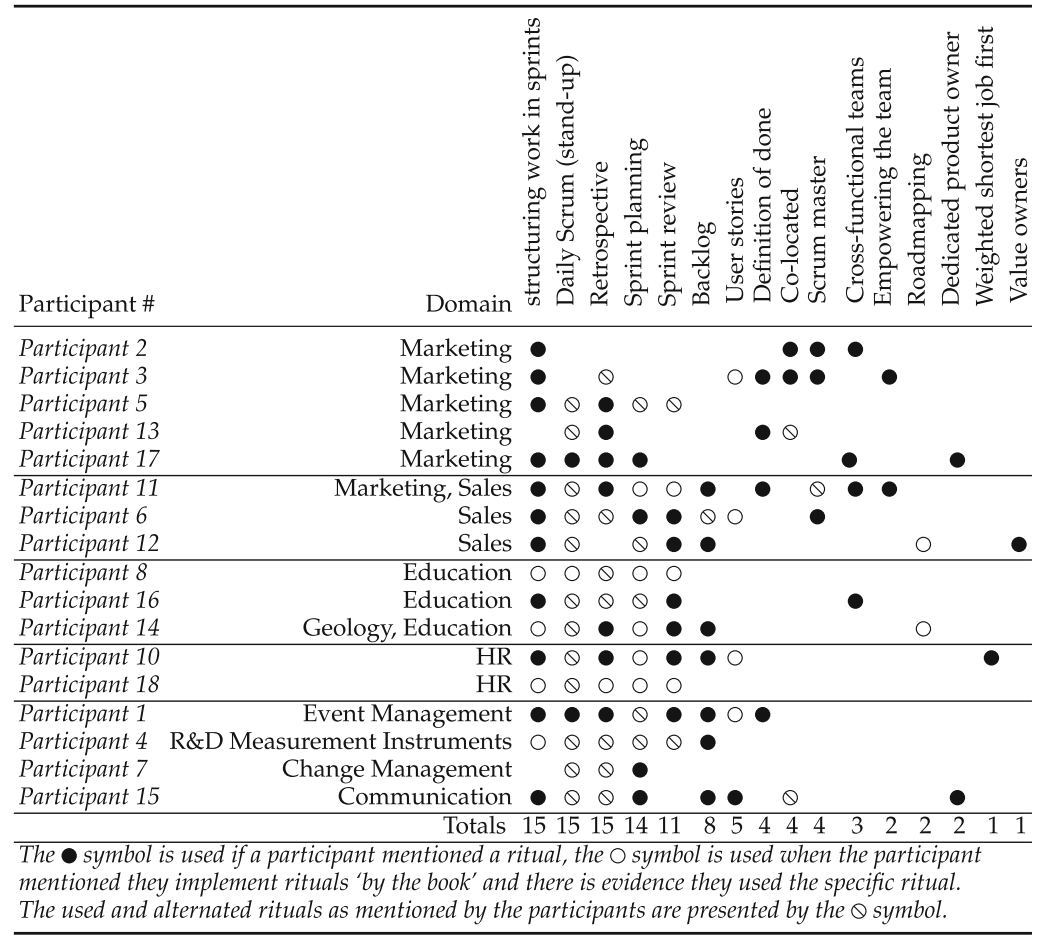

it hard to express themselves. This [The retrospective] was stopped" (Participant 6, Director Online Sales and Services, Program Manager).

Education: In education, we found that all participants implemented rituals such as a Sprint frequency, a daily Scrum, retrospectives, Sprint planning and Sprint reviews. The application of Scrum at schools was based on an altered version of Scrum and was implemented to enable students to organise their work. The rituals were shortened to fit in with student schedules. The teacher performed the role of Product Owner, but he/she also guided the process as the Scrum Master. Participant 16 described Scrum as follows: "Students have more fun, results are better, [they] have ownership. Teachers can be a teacher again, have a coaching role, [feel] less pressure." It can be assumed that applying Scrum in schools was successful, in that teaching staff subsequently adopted it; in addition, an added benefit was that, when students applied for jobs or when they continued their education, they were already familiar with Scrum and tended to apply to places where Scrum was used.

Human Resources: Two participants shared their experiences with Agile ways of working within the domain of human resources. Both mentioned that the 
application of Scrum formed the starting point, and was applied to a small-scale project. Scrum was implemented following the Scrum guidelines [10]. The daily Scrum ritual had to be altered, since the team was not at the same location every day. Participant 13 explained that they could not find a moment where they were all available at the same time. The solution was to have a planned conference call daily, so that the status of the project could be shared by the whole team: "Because everyone was across the country, it became a daily phoneup to update everyone [about] the work at hand" (Participant 10, Manager of Methods, Quality and Technology).

Communication: In the communication domain, only one example of Agile ways of working was found. This team used Agile to create an overview of the tasks at hand (transparency). They then started working in iterations (Sprint frequency), and had a daily Scrum, a retrospective and a Sprint planning session. The retrospective was stopped because of the lack of follow-up by the team. Respondent 15 explained this in the following way: "Reflection happened, but not in an orderly matter. They did make a mark if something went wrong, but did not [provide a] follow-up on how to improve. There was a feeling this would only cost [more] time" (Participant 15, Head of the Communications Team).

Success in implementation took place when room for making errors was factored in and when the surrounding teams were involved in the process. An additional success factor involved the crucial element of starting with people who were enthusiastic about applying Scrum. These people would then spread the news about the success of Scrum throughout the organisation.

Geology: In the domain of geology, the application of Scrum was twodimensional. First the team searched and made calculations related to drilling operations and secondly they started drilling. To prevent errors being made during the drilling process, the first part of the process (research and calculation) is done using an Agile way. Working with a backlog, daily stand-up meetings and retrospectives, respondent 14 explained the team could work efficiently and when research was going nowhere they could stop early in the process. This made the team effective by reducing the time prior to the drilling phase.

\subsection{Domains Where Agile Methods Could Be Applied in the Future}

This section explores potential applications of Agile management methods in domains where they have not yet been tried. Based on the findings from this study, we provide a trajectory of where we expect Agile management methods to be explored in the future; these tentative explorations would involve experimentation and additional research studies; in other words, the approach taken needs to involve both academic and professional/business applications.

Firstly, we compared the shared characteristics identified across our cases with the enablers presented by Conforto et al. [5] and organised them along the dimensions of Structure, Process, Culture and Nature of work as presented 
in Table 3. The main enablers on the intersection as discussed by our participants and literature were: Team-based work, Continuous improvement, Learning organisation and Customer involvement.

Secondly, in order to understand potential fields that are ripe for Agile applications, we looked at the current reports on work trends involving both the academic and professional domains, such as those provided by the European Trade Union Institute [31]; Accenture [32]; and $\mathrm{PwC}$ [33], as well as academic research $[34,35]$. The workforce trends commonly discussed in these reports are linked to digitisation, flexible work arrangements and work taking place in ecosystems, and the importance of a work/life balance. This section focuses on the impact of digitisation as the trend that is commonly acknowledged as having the biggest potential future impact. Specifically, the categories of Frey and Osborn [34] have been used to guide the discussion. In their article [34], Frey and Osborn present their views on the probability of computerisation. The domains they mark as less likely to be automated are domains where Agile methods could be applied. Jobs in domains that require creativity and those which are based on (cross-functional) teams are less affected by computerisation.

When looking at the findings of Frey and Osborn, it becomes apparent that there are some domains representing jobs that are not threatened by automation. Because Agile management methods are team-based methods, it is interesting to look at creative work fields that fit the criteria iterated above, especially those with high employment and the low probability of computerisation. As many manual tasks will be automated in the future, the human workforce fulfilling creative tasks will be expected to work more effectively in the future. Further, looking more in depth, skill sets of empathy and support, management and leadership, and science and engineering will require a major increase in the future according to labour market reports [36]. This shift towards creative work could open up further demands for Agile methods in other domains.

We picked four categories from Frey and Osborn [34] on the basis of two factors: (1) future occupational employment, and (2) low probability of computerisation. These two factors meant that a human workforce was required, and thus these categories shared characteristics of Agile management as discussed above.

In the management, business and financial category, the authors foresee a further application of Agile in the domains of change management, business development and Agile project and portfolio management in general. Furthermore, many organisations today are shifting their focus from being processcentred to being people-centric by changing previous management styles into those that involve leadership and collaboration [37]. The emergence of frameworks and methods that specifically focus on such domains as design thinking, lean start-ups, growth hacking, beyond budgeting and so on are all providing the impetus to change these domains and make them Agile.

In the computer, engineering and science domains, in addition to software development and engineering, which were the domains where Scrum was originally applied, the authors foresee an application of Agile methods to engi- 
Table 3. Enablers for use of Agile methods outside software projects

\begin{tabular}{|c|c|c|c|c|c|}
\hline Participant / Source & Domain & 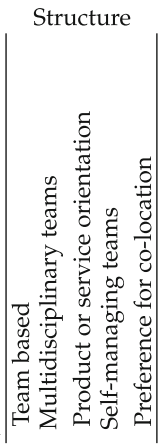 & 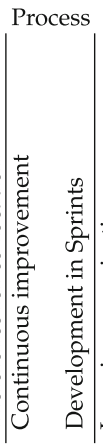 & 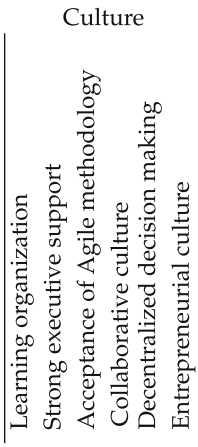 & 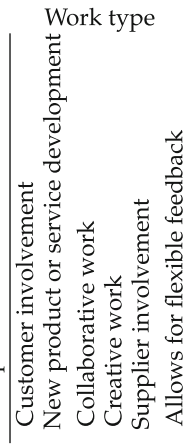 \\
\hline Conforto et al [5] & & 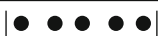 & $\bullet$ & - & \\
\hline Participant 2 & Marketing & $\bullet \bullet$ & $\bullet$ & & $\bullet$ \\
\hline Participant 3 & Marketing & & & & \\
\hline Participant 5 & Marketing & & & & 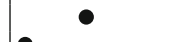 \\
\hline Participant 13 & Marketing & & & & \\
\hline Participant 17 & Marketing & $\bullet \bullet$ & $\bullet$ & & $\bullet \bullet$ \\
\hline Participant 11 & Marketing, Sales & $\bullet$ & & $\bullet$ & \\
\hline Participant 6 & Sales & $\bullet \bullet$ & & & $\bullet \bullet \bullet$ \\
\hline Participant 12 & Sales & & $\bullet \bullet$ & $\bullet \bullet \bullet$ & - $\bullet$ \\
\hline Participant 8 & Education & & & & \\
\hline Participant 16 & Education & & & & \\
\hline Participant 14 & Geology, Education & & - & & $\bullet \bullet$ \\
\hline Participant 10 & HR & $\bullet \bullet$ & - & $\bullet$ & \\
\hline Participant 18 & HR & $\bullet$ & - & $\bullet$ & \\
\hline Participant 1 & Event Management & $\bullet$ & $\bullet$ & & \\
\hline Participant 4 & R\&D Measurement Instruments & & & & \\
\hline Participant 7 & Change Management & & & & $\bullet \bullet$ \\
\hline Participant 15 & Communication & & - & & \\
\hline
\end{tabular}

neering. Many engineering disciplines have developed more flexible development and prototyping technologies, thus allowing for more flexible and more iterative feedback. While 3D printing and programmable logic facilitate faster industrial design and hardware development cycles, Agile and iterative management might prove useful only in the design stages of a construction project (such as building a bridge). Potential applications can also be found in the growing demand for data science projects, research projects in general, as well as in architecture.

Besides the case involving the use of Scrum in relation to education that was presented here, it is envisaged that the use of Scrum can foster enhanced student engagement (participant 16); in addition, we foresee an application in the design and coordination of educational programmes and in team-based course assignments in the domains of education, law, community service, arts and media.

In the healthcare practitioners and technical domains, there are examples of an Agile way of working being applied to make organisations or domains more responsive to their surroundings. Some examples involve community care in the Netherlands, a domain which is being changed by a new way of working (as applied by Buurtzorg [25]). Medical care in the Netherlands is changing towards a structure of self-supporting entities. This presents a challenge in 
relation to regional hospitals. Several hospitals have responded by shifting their focus towards the patient [38]. By using multidisciplinary teams at the first-aid post, an expert is immediately available because he/she is part of the team. This makes the care provided more effective for the patient. Earlier applications of this approach can be found in the domain of clinical operating teams [39] which, while needing to stay close to medical protocols in the operating theatre, need to adapt to the local needs of a particular patient and learn from those.

\section{$5 \quad$ Limitations}

Bias and Participant Sampling: The pool of participants was made up of (among others) managers, Agile coaches, consultants and researchers. Those interviewed were chosen based on their expertise in the topics under discussion. However, since they performed leadership or consulting roles in the application of Scrum, this could result in biased answers, especially when participants were asked about the perceived success of the implementation of Agile methods within their organisations. Furthermore, using Google and LinkedIn as the basis of a web search when looking for participants may have led to a biased sample, as these searches offer personalised results. Moreover, the majority of the participants were part of the researchers' personal network. While this allowed for targeting potential participants based on perceived expertise, it could make replication of the results of the study difficult.

Reliability: Only one person per discussed implementation was interviewed with the exception of one case, in which two participants were interviewed. Crosschecking claims by interviewing another person within the organisation could make the results more reliable. During interviews, some participants were found to take examples from previous experience on software development teams. When talking about Agile methods, it may be difficult for participants to separate their experience outside the software development context from their experience within IT. We tried to mediate this issue by reminding the participant during the interview that the main focus was on applications outside software development, if we noticed that a participant gave an example that clearly related to software development. However, we cannot guarantee that this solved the issue completely, as we asked participants questions about their experiences which they had to answer based on memory and interpretation.

\section{Conclusions}

Based on interviews with 18 experts, we came to a number of conclusions involving the use of Scrum and of Agile methods in general. Firstly, we identified those organisations applying Scrum in six domains (marketing, sales, communication, education, human resources and research projects). Secondly, we present, based on our cases and the enablers as identified by Conforto et al. [5], characteristic 
enablers for the successful application of Scrum in non-IT environments. Thirdly, we identified the most applied practices that were used in successful Agile implementation outside of IT (iterations in short frequencies; daily Scrum (Stand-ups), retrospectives, Sprint planning, Sprint review and backlogs). And fourthly, we identified four fields where, potentially, Agile methods could be applied (management, business and financial; computer, engineering and science; education, legal, community service, arts and media; and healthcare, practitioners and technical).

In addition, we found that companies and departments were often inspired by the success of Scrum in IT environments, and that while participants perceived that retrospectives were important, this ritual was often neglected [8]. Finally, we conclude that there is a strong potential for Agile project management expanding into domains yet untouched by this management method (including in domains not mentioned in this study). As organisations are inspired to implement Agile methods, we would like to invite researchers and change agents to actively apply Agile project management to new domains through action research and experiments, thus breaking down barriers to the future global expansion of Agile methods and techniques.

Acknowledgments. We thank all the participants for generously contributing to this study. We would like to also especially thank Nina Kojevnikov PhD. for her review, comments and critical notes.

\section{References}

1. Beck, K., et al.: Manifesto for agile software development (2001)

2. Conboy, K., Fitzgerald, B.: Toward a conceptual framework of agile methods: a study of agility in different disciplines. In: Proceedings of the 2004 ACM Workshop on Interdisciplinary Software Engineering Research, pp. 37-44. ACM (2004)

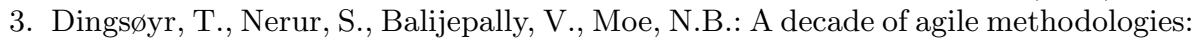
towards explaining agile software development (2012)

4. Abrahamsson, P., Conboy, K., Wang, X.: 'Lots done, more to do': the current state of agile systems development research (2009)

5. Conforto, E.C., Salum, F., Amaral, D.C., Da Silva, S.L., De Almeida, L.F.M.: Can agile project management be adopted by industries other than software development? Proj. Manag. J. 45(3), 21-34 (2014)

6. Conboy, K.: Agility from first principles: reconstructing the concept of agility in information systems development. Inf. Syst. Res. 20(3), 329-354 (2009)

7. Laanti, M., Similä, J., Abrahamsson, P.: Definitions of agile software development and agility. In: McCaffery, F., O'Connor, R.V., Messnarz, R. (eds.) EuroSPI 2013. CCIS, vol. 364, pp. 247-258. Springer, Heidelberg (2013). https://doi.org/10.1007/ 978-3-642-39179-8_22

8. Stettina, C.J., Hörz, J.: Agile portfolio management: an empirical perspective on the practice in use. Int. J. Proj. Manag. 33(1), 140-152 (2015)

9. Laanti, M., Salo, O., Abrahamsson, P.: Agile methods rapidly replacing traditional methods at Nokia: a survey of opinions on agile transformation. Inf. Softw. Technol. 53(3), 276-290 (2011) 
10. Schwaber, K., Sutherland, J.: The scrum guide. The Definitive Guide to Scrum: The Rules of the Game (2016)

11. So, C., Scholl, W.: Perceptive agile measurement: new instruments for quantitative studies in the pursuit of the social-psychological effect of agile practices. In: Abrahamsson, P., Marchesi, M., Maurer, F. (eds.) XP 2009. LNBIP, vol. 31, pp. 83-93. Springer, Heidelberg (2009). https://doi.org/10.1007/978-3-642-01853-4_11

12. Williams, L.: What agile teams think of agile principles. Commun. ACM 55(4), 71-76 (2012)

13. van Solingen, R., Sutherland, J., de Waard, D.: Scrum in sales: how to improve account management and sales processes. In: 2011 Agile Conference, pp. 284-288. IEEE (2011)

14. Steenberg, R.: The impact of measures when optimising sales processes using scrum, February 2016. (Working Paper)

15. Melnik, G., Maurer, F.: Introducing agile methods in learning environments: lessons learned. In: Maurer, F., Wells, D. (eds.) XP/Agile Universe 2003. LNCS, vol. 2753, pp. 172-184. Springer, Heidelberg (2003). https://doi.org/10.1007/978-3540-45122-8_20

16. Hicks, M., Foster, J.S.: Score: agile research group management. Commun. ACM 53(10), 30-31 (2010)

17. Stettina, C.J., Zhou, Z., Bäck, T., Katzy, B.: Academic education of software engineering practices: towards planning and improving capstone courses based upon intensive coaching and team routines. In: 2013 IEEE 26th Conference on Software Engineering Education and Training (CSEE\&T), pp. 169-178. IEEE (2013)

18. Jin-Hai, L., Anderson, A.R., Harrison, R.T.: The evolution of agile manufacturing. Bus. Process. Manag. J. 9(2), 170-189 (2003)

19. Agarwal, A., Shankar, R., Tiwari, M.: Modeling the metrics of lean, agile and leagile supply chain: an ANP-based approach. Eur. J. Oper. Res. 173(1), 211-225 (2006)

20. Manivelmuralidaran, V.: Agile manufacturing-an overview. Int. J. Sci. Eng. Appl. 4(1), 156-159 (2015)

21. Inman, R.A., Sale, R.S., Green Jr., K.W., Whitten, D.: Agile manufacturing: relation to JIT, operational performance and firm performance. J. Oper. Manag. 29(4), 343-355 (2011)

22. Drumond, C.: Agile marketing: fad or future of marketing? (2016). Accessed 1 July 2016

23. Ewel, J., et al.: Marketing manifesto (2018). Accessed 22 Aug 2018

24. King, E., K.V.: Success story: agility and health care, 2 February 2018

25. Gray, B.H., Sarnak, D.O., Burgers, J.S.: Home care by self-governing nursing teams: the Netherlands' Buurtzorg model (2015)

26. Hegarty, C.: Breaking departmental silos: scrum in finance, 9 June 2011

27. SCRUMstudy: How HR teams can benefit from scrum, 27 December 2013. Blogpost: http://blog.scrumstudy.com/how-hr-teams-can-benefit-from-scrum/

28. Gothelf, J.: How hr can become agile (and why it needs to), 19 June 2017. Blogpost on HBR.org: https://hbr.org/2017/06/how-hr-can-become-agile-and-why-itneeds-to

29. Zhang, H., Easterday, M.W., Gerber, E.M., Rees Lewis, D., Maliakal, L.: Agile research studios: orchestrating communities of practice to advance research training. In: Proceedings of the 2017 ACM Conference on Computer Supported Cooperative Work and Social Computing, pp. 220-232. ACM (2017)

30. Strauss, A., Corbin, J.M.: Basics of Qualitative Research: Grounded Theory Procedures and Techniques. Sage Publications, Inc., Thousand Oaks (1990) 
31. Degryse, C.: Digitalisation of the economy and its impact on labour markets (2016)

32. Accenture: Workforce marketplace: invent your future (2018)

33. PwC: Workforce marketplace: invent your future (2017)

34. Frey, C.B., Osborne, M.A.: The future of employment: how susceptible are jobs to computerisation? Technol. Forecast. Soc. Change 114, 254-280 (2017)

35. Katzy, B.R., Stettina, C.J., Groenewegen, L.P., de Groot, M.J.: Managing weak ties in collaborative work. In: 2011 17th International Conference on Concurrent Enterprising (ICE), pp. 1-9. IEEE (2011)

36. Accenture: It's learning. Just not as we know it (2018)

37. Nerur, S., Mahapatra, R., Mangalaraj, G.: Challenges of migrating to agile methodologies. Commun. ACM 48(5), 72-78 (2005)

38. Kim Bos, J.W.: NRC article: reward for less care, 23 September 2017. https:// www.nrc.nl/nieuws/2017/09/23/beloond-voor-minder-zorg-12248867-a1574534

39. Stettina, C.J., Groenewegen, L.P., Katzy, B.R.: Structuring medical agility. In: HEALTHINF, pp. 614-617 (2011)

Open Access This chapter is licensed under the terms of the Creative Commons Attribution 4.0 International License (http://creativecommons.org/licenses/by/4.0/), which permits use, sharing, adaptation, distribution and reproduction in any medium or format, as long as you give appropriate credit to the original author(s) and the source, provide a link to the Creative Commons license and indicate if changes were made.

The images or other third party material in this chapter are included in the chapter's Creative Commons license, unless indicated otherwise in a credit line to the material. If material is not included in the chapter's Creative Commons license and your intended use is not permitted by statutory regulation or exceeds the permitted use, you will need to obtain permission directly from the copyright holder. 